\title{
Debt collectors channel cash to corals
}

Damaged by divers, pollution and climate change, coral reefs may soon be protected through debt forgiveness. The US Congress is expected to approve a bill that would cancel foreign debt in developing countries in exchange for coral reef and rainforest conservation.

The Tropical Forest and Coral Conservation Act of 2007 sailed through the Senate's foreign-relations committee on 11 September. The full Senate and House of Representatives should take up the bill soon, and it could reach President George W. Bush - a supporter - by the end of 2007, says Mark Helmke, a senior adviser

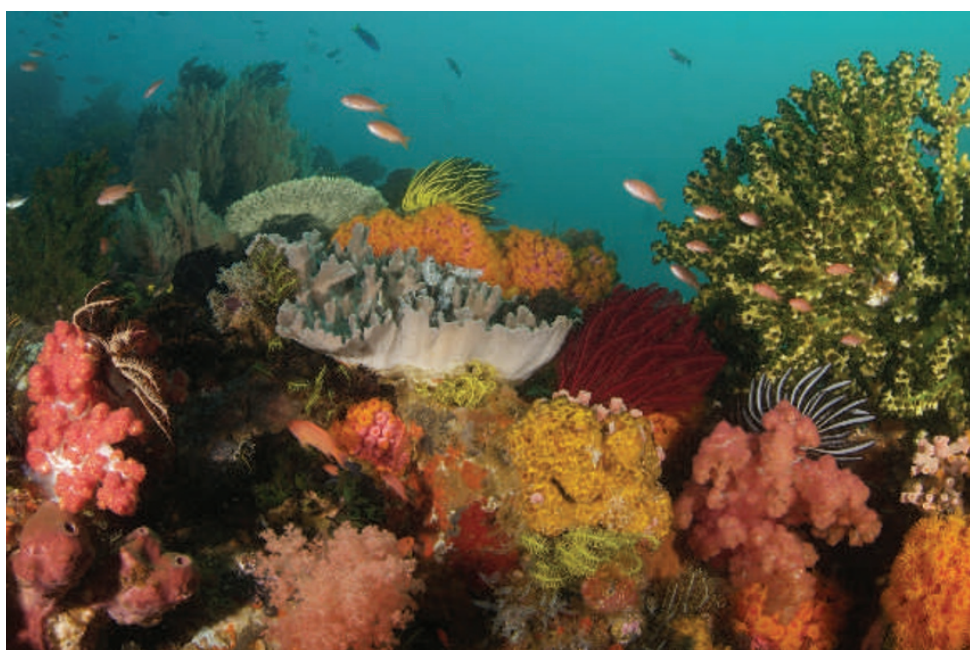

Indonesia could be the first country to swap national debt for corals.

tect the Chagres National Park. The money is being spent on projects such as park-boundary enforcement to stem illegal farming and training locals as ecotourist guides.

Indonesia is likely to be the first country to take up the debt-for-coral swap. Its Coral Triangle, home to more than 600 species of coral and 3,000 species of fish, is under threat from pollution, overfishing and bleaching - a situation exacerbated by global warming.

"Corals are in a tricky position because of climate change," says Lara Hansen, chief scientist for climate change with the conservation group WWF for Senator Richard Lugar (Republican, Indi- Bangladesh and Botswana. Under the deal, ana), one of the bill's sponsors. The bill provides $\$ 75$ million to pay off debts owed to the United States over the next three years.

Congress passed a similar bill in 1998 that has channelled $\$ 137$ million to protect rainforests in developing countries such as Panama, countries in debt to the US Agency for International Development give money to local conservation groups. In return, the United States cancels the same amount of debt. For example, in 2003, the US government cancelled $\$ 10$ million in debt owed by Panama to pro-

in Washington DC, which has helped to broker rainforest protection. "Even if you protect a coral spatially, you still have this massive threat." But any measure that relieves stress on reefs will buffer against damage from warming, she adds.

Ewen Callaway

\section{Malaria research should go 'back to basics'}

Efforts to wipe out malaria must stop squandering resources on trials of ineffectual vaccines and focus instead on generating better candidates, according to a report released on 17 September by the George Institute for International Health in Sydney, Australia.

The report looked at the status and future prospects of 47 vaccines and 21 drugs in various stages of development. The vaccine furthest along is one developed by GlaxoSmithKline (GSK). It should enter large-scale, phase III trials in 2008, with licensing pegged for 2012. The vaccine nearly halved severe malaria in a 2005 trial in 2,000 children younger than 5 years in Mozambique (P. L. Alonso et al. Lancet 366, 2012-2018; 2005). But the report comes down hard on the other vaccines. Far too many have been tested in clinical trials, in which most are certain to fail, eating up resources, says lead author Mary Moran, director of health policy at the George Institute. "You can't have all this stuff going to the field, you have to start weeding them out," she says.

But GSK's vice-president of clinical development, Ripley Ballou, argues that clinical tests are the only way to determine whether a vaccine works or not, and says that the trials can be done relatively cheaply. "For a couple of million dollars you can do a clinical study and kill a product if it doesn't work," he says.

Moran's team is calling for more basic research into malaria and the Plasmodium parasites that cause the disease. "There's not much new science coming into the field," agrees Stephen Matlin of the Geneva-based Global Forum for Health Research. Researchers barely know how humans fend off malaria, he points out, an insight that would help vaccine-makers to focus their efforts.

But Pedro Alonso, a researcher at the University of Barcelona in Spain who led trials of the GSK vaccine, says that the world shouldn't wait for science to catch up before going forward with malaria vaccines. "I worry that other vaccines aren't

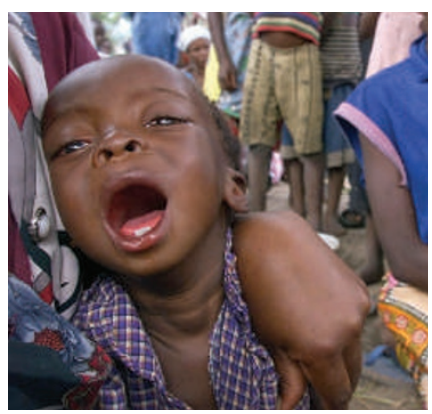

Malaria kills at least 1 million a year. doing as well," he says. But they shouldn't be abandoned. "It is not healthy to rely on just one candidate. Things can go wrong."

Despite large donors such as the US National Institutes of Health and the Gates Foundation infusing the field with cash, much more money is needed, the report claims. At least $\$ 560$ million will be required over the next five years to see current vaccines and drugs through development and clinical trials, Moran's team says. The report also calls for more cooperation between people who talk regularly but don't often work together. Such coordination would make more efficient use of the 23 clinical test sites for malaria vaccines in Africa. With so many vaccines moving forward, researchers could end up fighting for access to patients. Ewen Callaway 